\title{
Smith's Anesthesia for Infants and Children - Eighth Edition
}

\author{
Peter J. Davis, Franklyn P. Cladis, Etsuro K. Motoyama (Eds). Elsevier Mosby, 2011, \\ 1,356 pages. ISBN 978-0-323-06612-9
}

\author{
Robin G. Cox, MBBS
}

Received: 10 June 2011/Accepted: 17 June 2011/Published online: 24 June 2011

(C) Canadian Anesthesiologists' Society 2011

In this latest edition of one of the premier texts on pediatric anesthesia, Peter Davis replaces Etsuro Motoyama as principal editor and Franklyn Cladis assumes the role as the new third member of the editorial team. All are based at the Children's Hospital of Pittsburgh. Half a century has elapsed since Robert Smith, one of the "Fathers of Pediatric Anesthesiology", published the first comprehensive text on this subject, and subsequent editions have proven worthy of his legacy. This eighth edition is no exception.

The text retains its North American flavour with only four among the 91 chapter authors being non-U.S.A. contributors (from Canada, Australia, and South Africa). The book also retains its four main sections: "Basic Principles in Pediatric Anesthesia", "General Approach to Pediatric Anesthesia", "Clinical Management of Special Surgical Problems", and "Associated Problems in Pediatric Anesthesia". Many chapters have been reorganized, and some additional chapters are of great interest. Notable are new chapters that contain important background material, i.e., "Behavioural Development", "Neonatology for Anesthesiologists", and "Critical Care Medicine". Many chapters have been comprehensively rewritten by new authors, an excellent example being "Anesthesia for Congenital Heart Surgery". The text even devotes a chapter to an esoteric topic such as "Anesthesia for Conjoined Twins", which will be a major resource for those embarking on such cases. Also, a sign of our times is the addition of a section devoted to bariatric surgery in adolescents.

In general, the chapters are well written and current. As with the seventh edition, the chapter on "Regional Anesthesia" is a highlight and includes superb illustrations.

R. G. Cox, MBBS ( $\square)$

University of Calgary, Calgary, AB, Canada

e-mail: robin.cox@albertahealthservices.ca
In this chapter, significant attention is paid to ultrasonic techniques, both in the text and online. Other topics that reflect advances in pediatric surgery are well covered, e.g., anesthesia for minimal-access surgery in the neonate and the Nuss procedure for pectus excavatum. This reviewer was somewhat surprised that the chapter on neurosurgery did not address intraoperative magnetic resonance procedures that are becoming more widespread. As with any book with multiple authors, there is some overlap and repetition of material. This is not a problem per se, but there are instances where different authors offer slightly contradictory opinions. For example, in the chapter, "Preoperative Preparation", the author recommends a cardiology consultation if the anesthesiologist detects a previously undescribed murmur; however, in the chapter, "Anesthesia for Same-Day Procedures", the author states, "most skilled clinicians should be able to evaluate these murmurs". Since almost all of the authors are from the United States, they have contributed an American perspective to the text. In fact, some information applies only to the United States, particularly that relating to legislation and regulation. Additionally, the final chapter, "Medicolegal and Ethical Aspects", deals mainly with the medicolegal aspects; it would have been beneficial to include more of the many ethical issues relating to pediatric anesthesia.

This edition is striking for its excellent color illustrations, and clear diagrams, graphs, and clinical photographs. One important innovation in this edition is the seamless incorporation of web-based material via expertconsult.com. Indeed, once an account is activated, the entire book is available to the purchaser as a complementary online version. Each online chapter includes high-resolution files of all the figures included in the written text. Also, the reference list for each chapter no longer appears in hard 
copy but is available online. The advantage here is that the references include links to most articles cited. This reviewer found that a representative sampling of these links opened the respective references in PubMed. This allowed further access to complete manuscripts, as long as PubMed included free link access.

Additional web-based material includes video files and examination questions pertaining to each chapter. The video links are of reasonable quality, although not as consistent as the JPG images. The video material requires Adobe Flash Player to view, and this reviewer found that a few of the links did not open consistently despite assistance from the online support service. Generally, two or three review multiple choice questions and their respective answers are appended for each chapter. Regrettably, no explanation or reference is given for the correct answers, and with some questions, more than one answer may be correct. In general, the web-based material is a bonus and a distinct step up from the DVD provided with the previous edition.

Overall, the shortcomings of this text are very minor in nature. In my view, this new edition of Smith's Anesthesia for Infants and Children is a significant advance over previous editions, excellent though they may be. The latest printed and on-line material is clear, informative, current, and comprehensive. No anesthesiology department that cares for children should be without this resource in their library.

Competing interests None declared. 